\title{
The Bioavailability of Vitamin E in Fortified Processed Foods
}

\author{
Inga Schneider ${ }^{1}$, Ute Bindrich ${ }^{2}$, Andreas Hahn ${ }^{1}$ \\ ${ }^{1}$ Institute of Food Science and Human Nutrition, Leibniz University of Hannover, Hannover, Germany; ${ }^{2}$ German Institute of Food \\ Technologies, Quakenbrück, Germany. \\ Email: schneider@nutrition.uni-hannover.de
}

Received November $21^{\text {st }}, 2011$; revised January $16^{\text {th }}, 2012$; accepted January $23^{\text {rd }}, 2012$

\begin{abstract}
Objectives: Vitamin $\mathrm{E}$ is an important human lipophilic antioxidant and is required for many metabolic functions. A high vitamin $\mathrm{E}$ intake appears to favorably impact a variety of disease processes. The vitamin $\mathrm{E}$ intake, excluding supplemental intake, of the vast majority of adults is below the current recommended level. By consuming vitamin E-enriched food, it is possible to take in adequate amounts of vitamin E. Vitamin E intake from enriched foods might prevent certain diseases without the need to ingest specific vitamin $E$ supplements. The vitamin $E$ that is present in enriched foods has to exhibit maximal bioavailability to ensure a sufficient intake of vitamin $\mathrm{E}$ from one portion of fortified food. The aim of the present study was to develop an enriched food that has highly bioavailable vitamin E. Furthermore, we wanted to examine whether vitamin E bioavailability can be affected by the technological properties of fortified food. Methods: Volunteers were given test foods (cream cheese and mayonnaise) that had been fortified with $60 \mathrm{mg}$ of RRR- $\alpha$-tocopherol. The test foods were technologically modified and the bioavailability of RRR- $\alpha$-tocopherol was determined via a short-term kinetic measurement, which was $24 \mathrm{~h}$ long, and a long-term kinetic measurement, which was $28 \mathrm{~d}$ long. The test foods were characterized with respect to matrix properties. Results: In comparison to the mayonnaise group the serum $\alpha$-tocopherol area under the curve (AUC) was significantly higher in the cream cheese group, as shown in the short-term kinetic $(\mathrm{p}=0.010)$ and long-term kinetic $(\mathrm{p}=0.017)$ studies. Conclusions: In conclusion, RRR- $\alpha$-tocopherol was more bioavailable in cream cheese than in mayonnaise in both short-term and long-term periods. Hence, food matrices affect bioavailability of RRR- $\alpha$-tocopherol. Fortified foods with proven high $\alpha$-tocopherol bioavailabilities could be merchandised as functional foods with diseases prevention properties.
\end{abstract}

Keywords: Vitamin E; Bioavailability; Emulsion; Cream Cheese; Mayonnaise

\section{Introduction}

Vitamin $\mathrm{E}$ is a fat-soluble micronutrient that is required by humans for various metabolic functions. The most effective isomer of vitamin $\mathrm{E}$ is $\alpha$-tocopherol, which is a naturally occurring lipophilic antioxidant. Vitamin $\mathrm{E}$ is present in cell membranes, wherein it defends against lipid peroxidation and prevents free radical generation. Vitamin E plays an important role in the pathophysiology of several conditions, including cardiovascular disease [1]. High vitamin $E$ intake defends against a variety of disease processes, and vitamin $\mathrm{E}$ protects against deteriorating immune function, provides neuroprotection, and has anti-inflammatory functions [2]. Nevertheless, data from the National Health and Nutrition Examination Survey (NHANES 1999-2000) indicate that the majority of the U.S. population does not meet the current dietary recommendation of $15 \mathrm{mg} \alpha$-tocopherol/day [3]. The amount of vitamin $\mathrm{E}$ that is necessary to provide protec- tion from diseases cannot be gained by natural food alone. By consuming vitamin-E-enriched food it is possible to consume adequate amounts of vitamin $\mathrm{E}$. Therefore, it is possible to prevent certain diseases without the need for ingesting vitamin $\mathrm{E}$ supplements.

The absorption efficiency of vitamin $\mathrm{E}$ is between 15 and $65 \%$ [4]. Several factors can influence the bioavailability of vitamin E, some are associated with the individual (age, lifestyle), whereas others relates to the food (matrix, amount of fat, amount consumed, chemical forms of the nutrient) [5]. Generally, vitamin E must be given with meals and not on an empty stomach in order to achieve maximum absorption [6]. The bioavailability of natural RRR- $\alpha$-tocopherol is higher than that of synthetic all-rac- $\alpha$-tocopherol [7]. Encapsulated vitamin E is poorly absorbed even when consumed with a meal. Vitamin $\mathrm{E}$ bioavailability can be enhanced by fortifying food with vitamin E [8]. The bioavailability of vitamin E is influenced by the amount of dietary fat and the matrix 
of the food $[9,10]$.

The aim of the present study was to develop vitamin E-enriched foods that ensure a high vitamin E bioavailability. Volunteers were given test foods that were fortified with $\alpha$-tocopherol. $\alpha$-tocopherol bioavailability was determined via a short-term kinetic study which was $24 \mathrm{~h}$ long, followed by a long-term kinetic study, which was $28 \mathrm{~d}$ long. The test foods were characterized with respect to matrix properties. Furthermore, we examined whether $\alpha$-tocopherol bioavailability is affected by the matrix properties of the test foods.

Test food should be component of the subjects' normal nutrition. Because of the liposolubility of vitamin E, it should be integrated into foods that have relatively high fat contents. We chose two different emulsions as test foods (cream cheese and mayonnaise) with different matrices and composition to evaluate whether the bioavailability differs among different matrices. Cream cheese is a disperse system with multiple phases that consist of a casein micelle network, dispersed fat droplets, and a capillary system wherein the remaining whey is immobilized. Cream cheese has a $\mathrm{pH}$ value of about 4.5. For the cream cheese that was tested in this study, an emulsion with a fat content of $60 \%(\mathrm{w} / \mathrm{w})$ was prepared and mixed with curd instead of cream.

Mayonnaise is a concentrated oil-in-water emulsion that has a fat content of $50 \%-85 \%$ and a $\mathrm{pH}$ value of 3.8 - 4.0. Mayonnaise interfaces are stabilized by the protein-phospholipid complex of the egg yolk; however, these interfaces do not form a barrier that can prevent material transport processes. The continuous phase of the fat-reduced mayonnaise product contains water with the dissolved components, in addition to gelatinized starch, which forms a tri-dimensional network in the water phase and restricts barrier properties so as to permit molecular diffusion [11].

\section{Materials and Methods}

\subsection{Subjects and Study Design}

The study protocol was approved by Freiburger EthikKomission International, Germany (07/2015). Written informed consent was obtained from all subjects in accordance with the principles of the Helsinki Declaration.

Healthy young subjects were recruited from the general population by notice. Smoking, the intake of dietary supplements with vitamin $\mathrm{E}$, and diagnoses or suspicions of gastrointestinal disorders were defined as exclusion criteria. Inclusion and exclusion criteria were assessed via structured questionnaires before the intervention period and on the intervention days.

This study consisted of a short-term kinetic study and a long-term kinetic study. In each trial, subjects were asked to avoid foods that were rich in vitamin $\mathrm{E}$ to mini- mize intake variability. Restricted foods included vegetable oils, nuts, and cereals.

In the short-term kinetic study, five male volunteers (mean age $30 \pm 4$ years) were given one of two test foods (cream cheese or mayonnaise), which had been fortified with $60 \mathrm{mg}$ of RRR- $\alpha$-tocopherol, in a randomized order with a crossover design, and each study day was separated by $7 \mathrm{~d}$. On intervention days, each subject ingested a single portion of either cream cheese or mayonnaise after an overnight fast. The test food contained $5 \mathrm{~g}$ of fat and was given with a standard breakfast that contained $30.1 \mathrm{~g}$ of fat, $29.6 \mathrm{~g}$ of protein, $67.9 \mathrm{~g}$ of carbohydrate, $1.3 \mathrm{mg}$ of vitamin E, and $2771 \mathrm{~kJ}$ of energy. Subjects consumed standard meals and beverages over $24 \mathrm{~h}$. Blood samples were taken initially (pre-dose at baseline) as well as 1, 3, 5, 7, 9, 12, and $24 \mathrm{~h}$ after the intake of the test food.

In the long-term kinetic study, subjects were randomly assigned to one of two treatment groups (each $n=9$ ) and each took either one portion of either cream cheese or of mayonnaise that had been fortified with $60 \mathrm{mg}$ of RRR$\alpha$-tocopherol daily for 28 d. Randomization was conducted according to gender. Fasting blood samples were taken pre-dose and weekly during the experimental period.

\subsection{Test Foods}

Both test foods (cream cheese and mayonnaise) were prepared by the German Institute of Food Technologies (Quakenbrück, Germany) in a laboratory scale using a two-stage process. First starch was gelatinized in the water phase using a universal kitchen machine (Thermomix, Vorwerk, Germany) for the mayonnaise preparation. Pre-emulsification was done with a stirrer, and the emulsifying process was carried out again using the Thermomix. In order to make the cream cheese, curd was prepared according to the conventional production procedure (acid precipitation with cream cheese culture). Whey was removed from the curd by cutting the curd and subsequently removing the separated whey. The final dry matter (DM) content was adjusted by centrifugation. The emulsion was prepared using the Thermomix. The curd and emulsion were mixed until a homogeneous distribution was reached. The formulations of the test foods are presented in Table 1.

\subsection{Anthropometric Measurements and Blood Sampling Foods}

Subjects were examined by trained professionals according to standardized methods at the Institute of Food Science and Human Nutrition of Leibniz University, Hannover, Germany. Body weight was measured using a calibrated scale, body height was surveyed via tape measure, and body mass index (BMI) was calculated as 
Table 1. Formulations of the test foods.

\begin{tabular}{cccc}
\hline \multicolumn{2}{c}{ mayonnaise } & \multicolumn{3}{c}{ cream cheese } \\
\hline rapeseed oil & $49.80 \%$ & curd; $22.3 \% \mathrm{DM}^{\mathrm{a}}$ & $60.60 \%$ \\
water & $37.65 \%$ & water & $32.14 \%$ \\
past. egg yolk & $4.48 \%$ & rapeseed oil & $6.25 \%$ \\
Saccharose & $2.49 \%$ & Na-casein & $0.47 \%$ \\
modified starch; E1422 & $2.59 \%$ & $\mathrm{NaCl}$ & $0.31 \%$ \\
$\mathrm{NaCl}$ & $1.49 \%$ & Xanthan & $0.24 \%$ \\
vinegar; $5 \%$ acid & $1.49 \%$ & & \\
\hline
\end{tabular}

adry matter.

weight $(\mathrm{kg}) /$ height $(\mathrm{m})^{2}$. Blood samples were drawn using serum monovettes (Sarstedt, Germany). All measurements (blood values and evaluation of anthropometric data) were carried out on every intervention day.

\subsection{Serum Analyses}

In order to collect serum, blood samples were allowed to coagulate for $20 \mathrm{~min}$ prior to centrifugation $(2000 \mathrm{~g}, 10$ min, $10^{\circ} \mathrm{C}$ ). Serum samples were stored at $5^{\circ} \mathrm{C}$ and shipped on ice to an accredited laboratory (Laborärztliche Arbeitsgemeinschaft für Diagnostik und Rationalisierung e.V., Hanover, Germany). $\alpha$-tocopherol levels were measured by HPLC with UV-detection, and the results are expressed as $\mu \mathrm{mol} / \mathrm{L}$. Triacylglycerol (TG) and total cholesterol (TC) levels were enzymatically determined using automated standard laboratory methods (Olympus Life and Material Science Europa $\mathrm{GmbH}$, Hamburg, Germany), and the results are expressed as $\mu \mathrm{mol} / \mathrm{L}$.

\subsection{Material Characterization}

The particle size distribution was determined by light scattering measurements using a Malvern Mastersizer X laser diffraction analyzer. A prerequisite for the laser diffraction spectroscopy is a low particle concentration; hence the emulsions were diluted to $1: 20,000$ in a tetrasodium pyrophosphate solution. In this characterization technique, the light that is scattered by the droplets is detected as an angle-dependent intensity distribution. This diffraction pattern is converted into the volume distribution of the droplets using the mathematical background of Mie-theory. Based on the volume distribution the specific surface area (SSA) of the dispersed phase can be calculated. SSA is an integral value that describes the dispersed state of the emulsion. A further parameter is $X_{n}$ which describes the percentage volume (n) that is occupied by particles with a diameter that are less than a determined value. This parameter was used to calculate the average diameter and size dispersion coefficient $(\delta)$, which is defined as $\delta=\left(D_{90}-D_{10}\right) / D_{50}$.

The extractable fat content (EFC) was measured according to a method described by Kielmeyer and Schuster [12]. The intensities of material exchange processes in dispersed multiphase systems considerably depend on the state of the interfaces. Using this method, the quantity of fat that can be extracted from the dispersed phase by a non-polar solvent is determined. EFC values decreases with a higher density and stability of the interface.

\subsection{Mathematical and Statistical Analyses}

Data are presented as the mean \pm standard deviation (SD) for continuous variables, and the number of subjects (n) and percentage (\%), respectively, for categorical variables. The serum $\alpha$-tocopherol concentrations were adjusted to TC and TG levels. All serum levels were corrected to baseline levels $\left(t_{0}\right)$. The areas under the curve (AUC) of $\alpha$-tocopherol and adjusted $\alpha$-tocopherol values were calculated for each person for each study day according to the trapezoidal rule. The time-to-maximum concentration $\left(\mathrm{t}_{\max }\right)$ and maximal concentrations $\left(\mathrm{c}_{\max }\right)$ were identified by visual inspection of the data. Data were found to be normally distributed using the Kolmogorov-Smirnov test, and therefore parametric tests were used for the statistical analyses. An independent sample $\mathrm{t}$-test was used to reveal significant differences between the two intervention groups. All tests were two sided and a $p \leq 0.05$ was considered to be statistically significant. SPSS software (version 16.0; SPSS Inc, Chicago, IL, USA) was used for all of the statistical analyses.

\section{Results}

\subsection{Short-Term Kinetic Study}

Five healthy males participated in the short-term kinetic study. Their mean age was $30 \pm 4$ years, mean height was $1.80 \pm 0.07 \mathrm{~m}$, mean weight was $79.3 \pm 8.1 \mathrm{~kg}$, and mean BMI was $24.6 \pm 3.0 \mathrm{~kg} / \mathrm{m}^{2}$. Due to the crossover study design, baseline levels were not significantly different between the treatment groups.

The maximum concentration of $\alpha$-tocopherol was not significantly different in both treatments groups. $t_{\max }$ was significantly higher in the mayonnaise group than that in the cream cheese group. There were no significant differences between the two treatment groups in serum $\alpha$-tocopherol $\mathrm{AUC}_{0-24}$ levels or adjusted $\alpha$-tocopherol/TC $\mathrm{AUC}_{0-24}$ values; however, the adjusted $\alpha$-tocopherol/TC + TG $\mathrm{AUC}_{0-24}$ levels were significantly higher $(\mathrm{p}=0.010)$ in subjects after ingestion of cream cheese in comparison to those after the ingestion of mayonnaise. The pharmacokinetic levels of the short-term kinetic study are shown in Table 2 and Figure 1. 


\subsection{Long-Term Kinetic Study}

The characteristics of the long-term kinetic study population are presented in Table 3. No significant absolute differences in sexes or anthropometric variables were found between the two treatment groups.

There were no significant differences in the maximum concentration of $\alpha$-tocopherol or $t_{\max }$ following ingestion of cream cheese vs. mayonnaise. Likewise, the $\alpha$-tocopherol $\mathrm{AUC}_{0-4}$ values were similar after cream cheese and mayonnaise consumption. The adjusted $\mathrm{AUC}_{0-4}$ levels were significantly higher $\left[\mathrm{p}=0.018\right.$ for $\mathrm{AUC}_{0-4}$ $\left(\alpha\right.$-tocopherol/TC) and $\mathrm{p}=0.017$ for $\mathrm{AUC}_{0-4}(\alpha$-tocopherol/TC+TG)] after the ingestion of cream cheese vs. those after ingestion of mayonnaise.

The pharmacokinetic levels of the long-term kinetic study are summarized in Table $\mathbf{4}$ and Figure 2.

\subsection{Test Food}

The size distribution of the emulsion droplets was almost equal in the cream cheese and the mayonnaise, as was the boundary layer. The dispersion coefficient was nearly the same in both test foods as well (Table 5).

The EFC differed considerably between the two emulsions. The EFC of mayonnaise was about 16 times greater than that of cream cheese (Table 6).

\section{Discussion}

This study was designed to determine whether vitamin $\mathrm{E}$ from fortified cream cheese and mayonnaise is bioavailable when the fortified foods are consumed. A second aim of this study was to examine if the vitamin E bioavailability is affected by the technological properties of the fortified food. The results demonstrate that vitamin $\mathrm{E}$ is bioavailable from fortified cream cheese and mayonnaise. The bioavailability of $\alpha$-tocopherol was significantly greater in fortified cream cheese in comparison to fortified mayonnaise at $24 \mathrm{~h}$ and at $28 \mathrm{~d}$. Furthermore the time to reach the maximum serum concentration of

Table 2. Serum maximal concentration $\left(c_{\max }\right)$ and area under curve $\left(\mathrm{AUC}_{0-24}\right)$ - $\alpha$-tocopherol concentrations corrected to the baseline level and time-to-maximum concentration $\left(t_{\max }\right)$ in the cream cheese and the mayonnaise group of the short-term kinetic study, means \pm SD.

\begin{tabular}{|c|c|c|c|}
\hline & cream cheese & mayonnaise & $\mathbf{p}^{\mathbf{a}}$ \\
\hline $\mathrm{c}_{\max }[\mu \mathrm{mol} / 1]$ & $3.9 \pm 2.0$ & $3.9 \pm 2.7$ & 0.999 \\
\hline $\mathrm{t}_{\max }[\mathrm{h}]$ & $5.4 \pm 1.7$ & $7.4 \pm 0.9$ & 0.046 \\
\hline $\begin{array}{c}\mathrm{AUC}_{0-24}(\alpha \text {-tocopherol }) \\
{[\mu \mathrm{mol} * \mathrm{~h} / 1]}\end{array}$ & $57.3 \pm 43.2$ & $55.2 \pm 35.2$ & 0.934 \\
\hline $\begin{array}{c}\mathrm{AUC}_{0-24} \\
\left(\alpha \text {-tocopherol/TC }{ }^{\mathrm{b}}\right) \\
{[\mu \mathrm{mol} * \mathrm{~h} / 1]}\end{array}$ & $0.016 \pm 0.004$ & $0.011 \pm 0.004$ & 0.089 \\
\hline $\begin{array}{c}\mathrm{AUC}_{0-24} \\
(\alpha-\text { tocopherol/TC } \\
{\left[\mu \mathrm{mol}^{\mathrm{b}}+\mathrm{TG}^{\mathrm{c}} / \mathrm{l}\right]}\end{array}$ & $0.011 \pm 0.004$ & $0.002 \pm 0.005$ & 0.010 \\
\hline
\end{tabular}

${ }^{a}$ t-test for independent variables (cream cheese vs. mayonnaise). ${ }^{b}$ total cholesterol. " triacylglyceride.

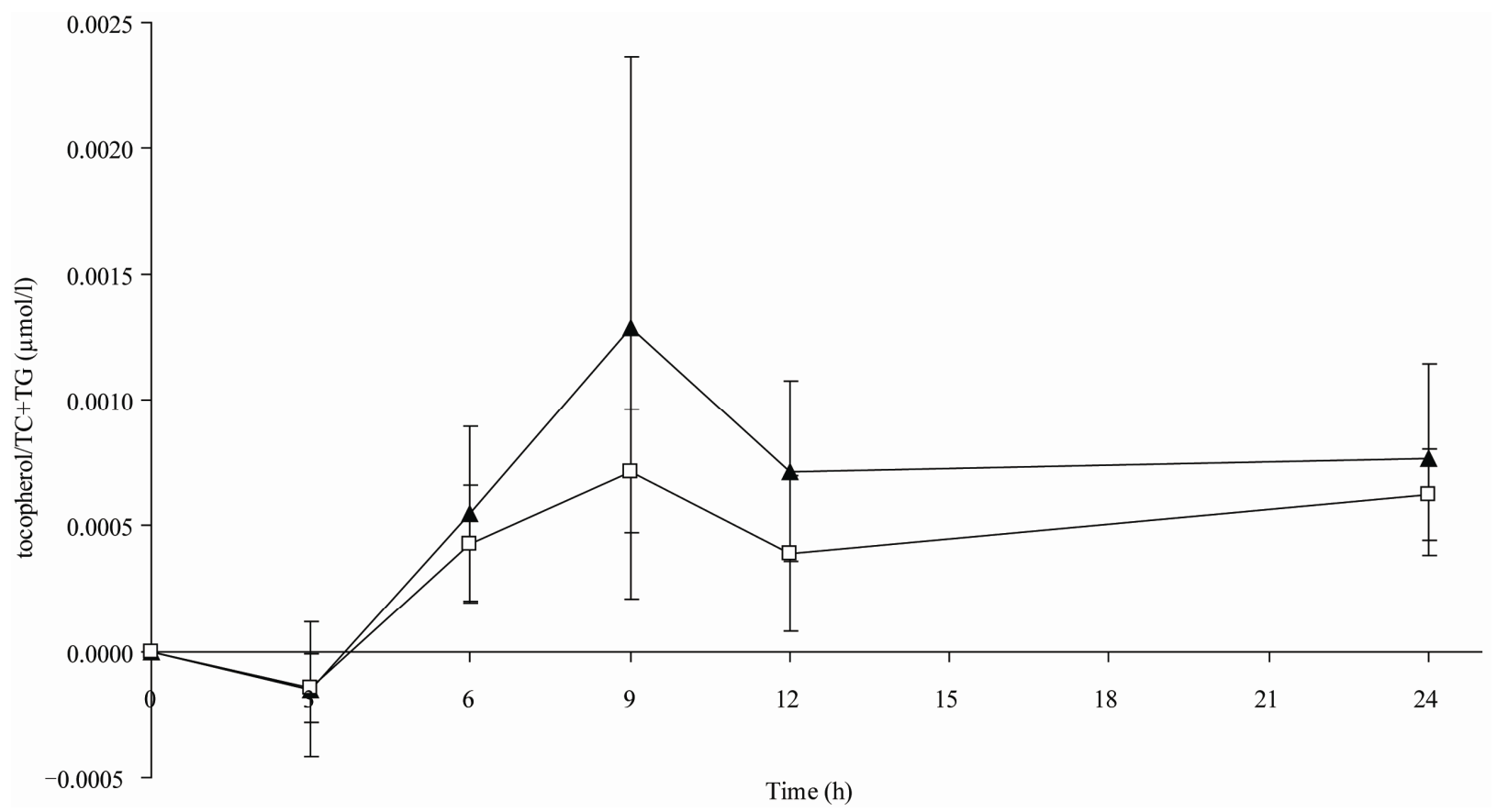

Figure 1. Mean serum $\alpha$-tocopherol/total cholesterol (TC) + triacylglyceride (TG) concentration corrected to the baseline level vs. time profiles after consumption of either cream cheese $(\Delta)$ or mayonnaise $(\square)$ fortified with $60 \mathrm{mg} \alpha$-tocopherol of the short-term kinetic study, $n=5$. 
$\alpha$-tocopherol was shorter in the cream cheese group than the mayonnaise group, indicating that $\alpha$-tocopherol was absorbed faster from the cream cheese. In addition, a relationship between the particle size of the emulsion and the bioavailability of $\alpha$-tocopherol was shown.

Short-term kinetics were measured by a crossover study, which demonstrated that the differences in $\alpha$-tocopherol bioavailability between mayonnaise and cream cheese are primarily caused by food matrix variation. The matrices of the administered test foods are characterized by the formulation and physical stabilization of the emulsions, both of which strongly depend on the interfacial properties of the proteins that assemble the interfaces. The ability of proteins to stabilize oil droplets in emulsions is influenced by their structure and conformation [13]. Proteins are adsorbed at the interfaces because of their amphiphilic properties. Interfacial properties are influenced by adsorbed amount, surface tension, network formation, and the possible conformational changes of proteins during and after adsorption [14]. The interfaces in mayonnaise are stabilized by the protein-phosphol-

Table 3. Characteristics of the study population of the longterm kinetic study, means \pm SD.

\begin{tabular}{cccc}
\hline & $\begin{array}{c}\text { cream cheese } \\
(\mathbf{n}=\mathbf{9})\end{array}$ & $\begin{array}{c}\text { mayonnaise } \\
(\mathbf{n}=\mathbf{9})\end{array}$ & $\mathbf{p}^{\mathbf{a}}$ \\
\hline Age $[\mathrm{y}]$ & $28.3 \pm 4.0$ & $26.1 \pm 4.6$ & 0.287 \\
Height $[\mathrm{m}]$ & $1.75 \pm 0.06$ & $77.2 \pm 11.2$ & 0.346 \\
Weight $\mathrm{t}_{0}[\mathrm{~kg}]$ & $70.2 \pm 13.7$ & $24.3 \pm 4.0$ & 0.255 \\
$\mathrm{BMI}^{\mathrm{b}} \mathrm{t}_{0}\left[\mathrm{~kg} / \mathrm{m}^{2}\right]$ & $22.8 \pm 3.4$ & $1.79 \pm 0.08$ & 0.382 \\
\hline
\end{tabular}

${ }^{a}$ t-test for independent variables (cream cheese vs. mayonnaise). ${ }^{b}$ body mass index.
Table 4. Serum maximal concentration $\left(c_{\max }\right)$ and area under curve $\left(\mathrm{AUC}_{0-24}\right)-\alpha$-tocopherol concentrations corrected to the baseline level and time-to-maximum concentration $\left(t_{\max }\right)$ in the cream cheese and the mayonnaise group of the long-term kinetic study, means \pm SD.

\begin{tabular}{|c|c|c|c|}
\hline & cream cheese & mayonnaise & $\mathbf{p}^{\mathbf{a}}$ \\
\hline $\mathrm{c}_{\max }[\mu \mathrm{mol} / 1]$ & $9.33 \pm 3.79$ & $8.33 \pm 4.41$ & 0.612 \\
\hline $\mathrm{t}_{\max }[\mathrm{h}]$ & $1.6 \pm 0.7$ & $1.2 \pm 0.4$ & $0.286^{\mathrm{b}}$ \\
\hline $\begin{array}{c}\mathrm{AUC}_{0-24}(\alpha \text {-tocopherol }) \\
{[\mu \mathrm{mol} * \mathrm{~h} / 1]}\end{array}$ & $20.6 \pm 11.8$ & $18.8 \pm 8.0$ & 0.709 \\
\hline $\begin{array}{c}\mathrm{AUC}_{0-24}(\alpha \text {-tocopherol/TC }) \\
{[\mu \mathrm{mol} * \mathrm{~h} / 1]}\end{array}$ & $0.007 \pm 0.003$ & $0.004 \pm 0.002$ & 0.018 \\
\hline $\begin{array}{c}\operatorname{AUC}_{0-24}\left(\alpha \text {-tocopherol } / \mathrm{TC}^{\mathrm{c}}+\mathrm{TG}^{\mathrm{d}}\right) \\
{[\mu \mathrm{mol} * \mathrm{~h} / 1]}\end{array}$ & $0.004 \pm 0.001$ & $0.002 \pm 0.001$ & 0.017 \\
\hline
\end{tabular}

${ }^{a}$ t-test for independent variables (cream cheese vs. mayonnaise); ${ }^{b} \mathrm{Mann}-$ Whitney-Test; ${ }^{\mathrm{c}}$ total cholesterol; ${ }^{\mathrm{d}}$ triacylglyceride.

Table 5. Droplet size distributions (D), specific surface area (SSA) and dispersion coefficient $(\delta)$ of test foods (cream cheese and mayonnaise) measured with a Malvern Mastersizer $\mathrm{X}$.

\begin{tabular}{cccccc}
\hline test food & $\mathbf{D 1 0}[\boldsymbol{\mu m}]$ & $\mathbf{D 5 0}[\boldsymbol{\mu \mathrm { m }}]$ & $\mathbf{D 9 0}[\boldsymbol{\mu \mathrm { m } ]}$ & $\boldsymbol{\delta}$ & $\mathbf{S S A}\left[\mathbf{m}^{2} / \mathbf{g}\right]$ \\
\hline cream cheese & 1.08 & 5.89 & 13.53 & 2.11 & 2.21 \\
mayonnaise & 1.42 & 4.32 & 11.58 & 2.35 & 2.14 \\
\hline
\end{tabular}

Table 6. Extractable fat content (EFC) of test foods (cream cheese and mayonnaise).

\begin{tabular}{cc}
\hline test food & EFC $[\mathbf{g} / \mathbf{1 0 0} \mathbf{g}$ fat $]$ \\
\hline cream cheese & $0.58 \pm 0.03$ \\
mayonnaise & $9.50 \pm 0.21$ \\
\hline
\end{tabular}

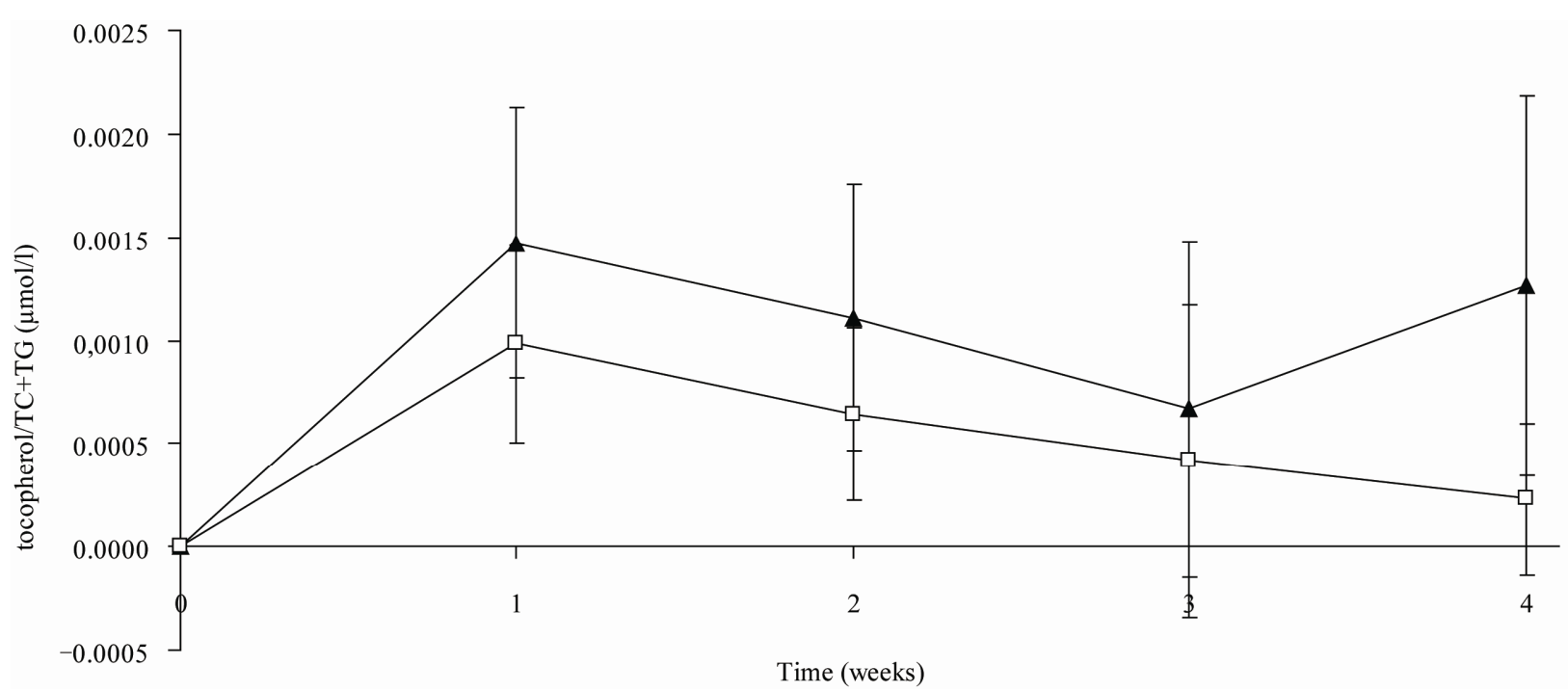

Figure 2. Mean serum $\alpha$-tocopherol/total cholesterol (TC) + triacylglyceride (TG) concentration corrected to the baseline level vs. time profiles after consumption of either cream cheese $(\Delta)$ or mayonnaise $(\square)$ fortified with $60 \mathrm{mg} \alpha$-tocopherol of the short-term kinetic study, $n=5$. 
ipid-complex of the egg yolk, whereas the boundary layer in cream cheese is formed by casein; however, the interface in mayonnaise seems to form a more unstable barrier in comparison to the cream cheese interface and is not able to prevent material transport processes [15]. For this reason, a higher absorption of $\alpha$-tocopherol was expected after mayonnaise consumption; however, our data indicate a higher $\alpha$-tocopherol bioavailability following the consumption of cream cheese. This unexpected result could be due to the salt that was used in the mayonnaise. The use of salt leads to a reduced energy barrier, which permits proteins to intrude into the network. The surface charge of the proteins is saturated by salt ions, such that the electric repulsion from proteins with identical charges is reduced. This leads to a very strong network and a stabilized mayonnaise emulsion [16]. Moreover, the disperse oil droplets are close packed, such that van der Waals forces further increase stability [17]. In summary, the interfaces of mayonnaise were stable to the point that $\alpha$-tocopherol absorption out of the oil droplets could have been impeded.

Cream cheese is a dispersed system with multiple phases consisting of a casein micelle network, dispersed fat droplets, and a capillary system wherein the remaining whey is immobilized. Casein forms chain-like structures that are connected with van der Waals forces, which lead to a robust and compact gel. Oil was added to the cream cheese to enhance the creamy characteristic. The oil droplets integrate into the casein micelle network and cause destabilization [18].

In addition to the compounds in the interface, the $\mathrm{pH}$ value of the food matrix can affect the absorption of $\alpha$-tocopherol. The secretion of the gastrointestinal hormone cholecystokinin is induced by duodenal chymus with $\mathrm{pH}$ value of approximately $4.0-4.5$. The release of cholecystokinin initiates the secretion of pancreatic enzymes for lipid digestion $[19,20]$. A test food with $\mathrm{pH}$ value in the range of the physiological intestinal $\mathrm{pH}$ value will lead to a release of cholecystokinin, and the release of cholecystokinin leads to a higher absorption of lipids and lipophilic $\alpha$-tocopherol. The $\mathrm{pH}$ value of mayonnaise is about $3.8-4.0$, whereas cream cheese has a $\mathrm{pH}$ value of about 4.5 ; hence, the bioavailability of $\alpha$-tocopherol from cream cheese should be larger than that of mayonnaise because the $\mathrm{pH}$ value of cream cheese is in the range of the physiological $\mathrm{pH}$ value of $4.0-4.5$ [11].

In addition to the compounds in the interface and the $\mathrm{pH}$ value of the food matrix, the total emulsifier content impacts the stability of the boundary layer and, by extension, the emulsion. Interfaces stability correlates with $\alpha$-tocopherol bioavailability. Robust interfaces make it harder for digestive enzymes to get across the interface into the oil droplets to absorb the $\alpha$-tocopherol. The mayonnaise contained slightly more emulsifiers than the cream cheese. The mayonnaise contained $4.48 \%$ egg yolk and $2.59 \%$ modified starch, whereas the cream cheese contained $7.39 \%$ whey protein from curd $(6.21 \%$ casein $)$ and additional $0.47 \%$ casein. Therefore, the bioavailability of $\alpha$-tocopherol should be greater in the cream cheese because it is less stable than the mayonnaise.

In summary, cream cheese seems to possess matrix characteristics that provide higher $\alpha$-tocopherol absorption, whereas the emulsion of mayonnaise seems to be more consistent with better digestion.

Increases in $\alpha$-tocopherol serum levels are limited. The $\alpha$-tocopherol values rose within the first week of investigation but remained stable thereafter. This saturation is due to an initially limited quantity of hepatic $\alpha$-tocopherol transfer protein $(\alpha$-TTP). An increased expression of $\alpha$-TTP can be induced by dietary $\alpha$-tocopherol [21]. $\alpha$-TTP serum levels increase until there is a complete occupation of the $\alpha$-TTP and decrease slightly thereafter because of an elevated hepatic $\alpha$-tocopherol metabolism [22]. The higher daily absorption of $\alpha$-tocopherol from cream cheese, in comparison to that of mayonnaise, leads to an increased expression of $\alpha$-TTP following the consumption of cream cheese. This finding was verified by a long-term kinetic study that indicates that the chronic administration of $\alpha$-tocopherol results in a steady serum level that occurred after $4-5 \mathrm{~d}$ of supplementation [23].

A physical characterization of the test foods was conducted to determine the potential bioavailability of $\alpha$-tocopherol. To our knowledge, this is the first study to evaluate whether $\alpha$-tocopherol bioavailability can be affected by the material properties of fortified food. These data suggest that size distributions of the emulsions droplets, as well as the expanse of the boundary layer, can be used as measures of $\alpha$-tocopherol bioavailability. A larger expanse of boundary layers causes a larger surface for digestive enzymes to absorb $\alpha$-tocopherol from fortified test foods. The size distribution of the emulsion droplets and the boundary layer did not differ between the cream cheese and the mayonnaise. Based on these data cream cheese and mayonnaise was expected to have equal $\alpha$-tocopherol bioavailabilities; however, our data indicate a higher $\alpha$-tocopherol bioavailability following the intake of cream cheese. EFC values can describe the permeability of the interface, and, therein the stability of the emulsion. These data can even be an indicator for the accessibility of the dispersed fat droplets to digestive enzymes. The two emulsions had very different EFC values. The extractable fat of the mayonnaise was about 16 times greater than that of cream cheese. The EFC value may relate to the amount of $\alpha$-tocopherol that can be absorbed from the test food. Nevertheless, our data show a significantly higher $\alpha$-tocopherol bioavailability following the consumption of cream cheese. Conse- 
quently, no correlation was found between the EFC and $\alpha$-tocopherol bioavailability.

In summary, these results indicate that the bioavailability of $\alpha$-tocopherol of fortified cream cheese was significantly higher than that of fortified mayonnaise, over both short-term and long-term period. The bioavailability of $\alpha$-tocopherol from fortified oil-in-water emulsions is influenced by interface properties. A technological characterization of the test foods has shown that particle size and boundary layer positively correlate with $\alpha$-tocopherol bioavailability; however, there is no relationship between the amount of extractable fat and the bioavailability of $\alpha$-tocopherol. In conclusion, fortified food with high $\alpha$-tocopherol bioavailabilities could be used to help people ingest adequate amounts of vitamin E. Fortified foods with proven high $\alpha$-tocopherol bioavailabilities could be merchandised as functional foods with disease prevention properties. Nevertheless, these results should be validated with additional kinetic studies. Future studies should be conducted with a variety of test foods with on oil-in-water emulsions, and there should be a detailed characterization of the technological properties of the food matrices.

\section{Acknowledgements}

We would like to thank the Ministry of Science and Culture of Lower Saxony (Germany) for funding this project through FAEN. Most of all, we would like to thank the participants who contributed their time to make this project successful.

\section{REFERENCES}

[1] C. Schneider, "Chemistry and Biology of Vitamin E," Molecular Nutrition \& Food Research, Vol. 49, No. 1, 2005, pp. 7-30. doi:10.1002/mnfr.200400049

[2] L. Packer, "Protective Role of Vitamin E in Biological Systems," American Journal Clinical Nutrition, Vol. 53, 1991, pp. 1050S-1055S.

[3] J. K. C. Ahuja, J. D. Goldman and A. J. Moshfegh, "Current Status of Vitamin E Nutriture," Annals of the New York Academy of Science, Vol. 1031, 2004, pp. 387-390. doi:10.1196/annals.1331.052

[4] M. G. Traber and H. Sies, "Vitamin E in Humans: Demand and Delivery," Annual Review of Nutrition, Vol. 16, 1996, pp. 321-347. doi:10.1146/annurev.nu.16.070196.001541

[5] P. Borel, "Factors Affecting Intestinal Absorption of Highly Lipophilic Food Microconstituents (Fat-Soluble Vitamins, Carotenoids and Phytosterols)," Clinical Chemistry and Laboratory Medicine, Vol. 41, No. 8, 2003, pp. 979-994. doi:10.1515/CCLM.2003.151

[6] L. Iuliano, F. Micheletta, M. Maranghi, G. Frati, U. Diczfalusy and F. Violi, "Bioavailability of Vitamin E as Function of Food Intake in Healthy Subjects: Effects on
Plasma Peroxide-Scavenging Activity and CholesterolOxidation Products," Arteriosclerosis, Thrombosis, and Vascular Biology, Vol. 21, No. 10, 2001, pp. E34-37. doi:10.1161/hq1001.098465

[7] A. R. Proteggente, R. Turner, J. Majewicz, G. Rimbach, A. M. Minihane, K. Krämer and J. K. Lodge, "Noncompetitive Plasma Biokinetics of Deuterium-Labeled Natural and Synthetic Alpha-Tocopherol in Healthy Men with an Apoe4 Genotype," Journal of Nutrition, Vol. 135, No. 5, 2005, pp. 1063-1069.

[8] S. W. Leonard, C. K. Good, E. T. Gugger and M. G. Traber, "Vitamin E Bioavailability from Fortified Breakfast Cereal Is Greater than That from Encapsulated Supplements," American Journal of Clinical Nutrition, Vol. 79, No. 1, 2004, pp. 86-92.

[9] Y. M. Jeanes, W. L. Hall, S. Ellard, E. Lee and J. K. Lodge, "The Absorption of Vitamin E Is Influenced by the Amount of Fat in a Meal and the Food Matrix," British Journal of Nutrition, Vol. 92, No. 4, 2004, pp. 575579. doi:10.1079/BJN20041249

[10] R. S. Bruno, S. W. Leonard, S. I. Park, Y. Zhao and M. G. Traber, "Human Vitamin E Requirements Assessed with the Use of Apples Fortified with Deuterium-Labeled Alpha-Tocopheryl Acetate," American Journal of Clinical Nutrition, Vol. 83, No. 2, 2006, pp. 299-304.

[11] H. D. Belitz, W. Grosch and P. Schieberle, "Lehrbuch der Lebensmittelchemie," Springer-Verlag, Berlin, 2008.

[12] F. Kielmeyer and G. Schuster, "Der Einfluß von Emulgatoren auf das Verhalten von Fett im Eismix während des Reifens," Fette, Seifen, Anstrichmittel, Vol. 88 , No. 10, 1986, pp. 397-401. doi:10.1002/lipi.19860881007

[13] K. P. Das and J. E. Kinsella, "Stability of Food Emulsions Physicochemical Role of Protein and Non-Protein Emulsifiers," Advances in Food and Nutrition Research, Vol. 34, 1990, pp. 181-201. doi:10.1016/S1043-4526(08)60007-8

[14] M. A. Bos and T. van Vliet, "Interfacial Rheological Properties of Adsorbed Protein Layers and Surfactants: A Review," Advances in Colloid and Interface Science, Vol. 91, No. 3, 2001, pp. 437-471. doi:10.1016/S0001-8686(00)00077-4

[15] S. R. Euston and R. L. Hirst, "The Emulsifying Properties of Commercial Milk Protein Products in Simple Oil-inWater Emulsions and in a Model Food System," Journal of Food Science, Vol. 65, No. 6, 2000, pp. 934-940. doi:10.1111/j.1365-2621.2000.tb09396.x

[16] W. Ternes, "Naturwissenschaftliche Grundlagen der Lebensmittelzubereitung," Behr's Verlag GmbH \& Co. KG., Hamburg, 2008.

[17] W. Flückiger, "Zur Technologie der Mayonnaise und mayonnaiseähnlichen Emulsionen," Fette, Seifen, Anstrichmittel, Vol. 68, No. 12, 1966, pp. 139-145.

[18] C. G. de Kruif, "Casein Micelle Interactions," International Dairy Journal, Vol. 9, 1999, pp. 183-188. doi:10.1016/S0958-6946(99)00058-8

[19] M. C. Carey, D. M. Small and C. M. Bliss, "Lipid Digestion and Absorption," Annual Review of Physiology, Vol. 45, 1983, pp. 651-677. 
doi:10.1146/annurev.ph.45.030183.003251

[20] S. J. DeNigris, M. Hamosh, D. K. Kasbekar, C. S. Fink, T. C. Lee and P. Hamosh, "Secretion of Human Gastric Lipase from Dispersed Gastric Glands," Biochimica et Biophysica Acta, Vol. 836, No. 1, 1985, pp. 67-72.

[21] H. Fechner, M. Schlame, F. Guthmann, P. A. Stevens and B. Rüstow, "Alpha- and Delta-Tocopherol Induce Expression of Hepatic Alpha-Tocopherol-Transfer-Protein mRNA," Biochemical Journal, Vol. 331, No. 2, 1998, pp.
577-581.

[22] J. H. Wu and K. D. Croft, "Vitamin E Metabolism," Molecular Aspects of Medicine, Vol. 28, No. 5-6, 2007, pp. 437-452. doi:10.1016/j.mam.2006.12.007

[23] N. V. Dimitrov, C. Meyer, D. Gilliland, M. Ruppenthal, W. Chenoweth and W. Malone, "Plasma Tocopherol Concentrations in Response to Supplemental Vitamin E," American Journal of Clinical Nutrition, Vol. 53, No. 3, 1991, pp. 723-729. 